\title{
The Welcoming Address
}

\section{Major General B Livesey}

It gives me great pleasure to give a warm welcome to the participants in the Leishmaniasis Centenary Event to the Royal Army Medical College.

It is particularly appropriate that the Royal Army Medical Corps has been given the opportunity to host this important academic milestone in the development of understanding and management of this fascinating and challenging condition.

The early development of an organised medical service, primarily geared to maintaining medical support for the needs of the military and colonial activities overseas, has been inextricably bound up with the development of Tropical Medicine.

The first Army Medical College was established on an ad hoc basis at the Royal Engineers Depot at Chatham in 1860 and moved in 1863 to the newly built military hospital at Netley near Southampton. The College moved to its current location in Millbank in 1907.

It is also my pleasure to welcome the distinguished guests of honour:

Colonel H E Shortt who has made invaluable contributions to our understanding of the transmission of leishmaniasis, and who was one of the pioneers of antimonial chemotherapy.

Professor P C C Garnham who has made many valuable contributions in tropical medicine, and who pioneered the aetiology studies into the South American Leishmanias.

Professor W Peters who is presently the Professor and Director of the Protozoology Department of the London School of Hygiene and Tropical Medicine, and who is a recognised expert on antileishmanial and antimalarial chemotherapy.

Dr D J Lewis who is a distinguished Leishmania entomologist. We congratulate him on being the recipient of the Christophers Medal.

Dr L P Joyner who as a student of J D Fulton was one of the pioneers of Leishmania biochemistry.

Lt Col R C Menzies who is the current Professor of Pathology at the Royal Army Medical College which has played such a central role in the history of leishmaniasis.

Several funding organisation who actively support leishmanial research are also represented: Dr Anthony Davis for The World Health Organisation, Dr Brigitte Ogilvie for the Wellcome Trust and Sir Christopher Booth for the British Medical Research Council.

It is a special pleasure to welcome on the conference's behalf Sir William Leishman's daughter, Mrs Bunty Davidson, who together with her husband has joined ug as a guest of honour.

Professor Leishman was appointed Professor Military Pathology in succession to Almroth Wright an held the chair from 1903-1913 in the RAM College unt he was Director of Army Pathology. His influence or the Army Medical Services and civilian practice was formidable.

It is fitting therefore that the deliberations of the Leishmaniasis Centenary Meeting are to be conducte in the immediate vicinity of Sir William Leishman' pathology ciepartment, and I have no doubt that ou $\vec{F}^{+}$ successors in 2085 will continue to have the same degree of admiration for this most distinguished officer.

\section{FRCP (Ireland)}

FFARCS - Final

MRCGP

MSc-Occupational Medicine

\section{ACADEMIC ACHIEVEMENTS}

- Lt Col T Graham, RAMC

-Major L Henderson, RAMC

- Capt B N B Dunlop, RAMC

- Capt P H Gilbert, RAMC

- Capt Helen L Grisewood, RAMC

- Capt P R Harvey, RAMC

- Maj G W Lawrenson, RAMC

- Capt D M Miles, RAMC

- Maj P R Stevenson, RAMC

Major S J Durnford, RAMC 